\title{
The Influence that Sports Information Technology Had on Modern Competitive Sports
}

\author{
Changsong HAN \& Xin CHEN* \\ Hubei Engineering University, China, Hubei
}

\begin{abstract}
Technological advances play an important role in the modern sports, which reveals the use of science everywhere, especially for the wider use of sports information technology. sports information technology as the applied sciences technology and sports practice. what's more, it is mostly needed more in developing sports practice and promoting modern competitive sports, by effective organization. through literature, expert interviews, logical analysis and other research methods this paper is to study modern competitive sports influenced by information technology, expound the application, development status and importance of information technology in modern competitive sports. the research shows that information technology plays a vital part in developing competitive sports, improving the justice competitiveness and ornamental, est. however, the deficiencies still exist in the application in formation technology in competitive sport. So scientific research department should give more support to the research, prove research institution, train high-tech men profession and exchange with other countries.
\end{abstract}

KEYWORD: sports information; technology; competitive sports; science and technology

\section{INTRODUCTION}

Science and technology as the primary productive force, are promoting the social development greatly. Therefore it's certain that the modern technology revolution will accelerate the modernization of competitive sport with the fast development of competitive sports, people set a higher demand on competitiveness and ornamental. fortunately in competitive sport, information technology is emerging as the times require. however the difference between traditional and modern way and the problem brought out by sports information technology should be considered so as to propose the strategy, have a better combination of sports information technology and competitive sports and have a continuous development of competitive sports analysis.

\section{THE RESULT AND THE ANALYSIS}

\subsection{Sports information technology}

\subsubsection{Sports information}

Sports information is the existing way of sports phenomenon, reflection of move status and one of sports universal attributes. that is to say sports need information to describe and the later is the formers' existing attribute. broadly speaking information is needed to display sports social function, the function of keeping a sound body and body tolerance. in a narrow sense not only sports performance, sports feeling training management and teaching organization require information but also sports communication, news knowledge and data. so sports information possesses all the attributes of information.

\subsubsection{The definition of sports information technology}

Sports information technology can defined narrowly and broadly. the narrow definition is to collect, record, analyze, dispose and make use of sports information. the broad definition is to know sports again in the sense of information, in other words, it is to make new description and definition generally. What's more the broad definition concludes sports related traditional and molder techniques and instruments e.g. manual stroke analysis, television signal, score system, computer network in communication.[1] Generally speaking sports information technology is defined as information production test, alternation; storage, transmission, disposal, demonstration, recognition, extraction and 
domination. Computer technology is the core of sports information technology but not all.

\subsection{The function of sports information technology}

\subsubsection{Sport information technology promotes the normalization of sports contests administration.}

With the network information technology integrating into sports area, computer network is resorted in large-scale international sporting events the information management of which involves personal management firstly. while personal concludes sportsmen, referees, managers and volunteers, and personal management involve registration and modification of personal information, whose accuracy is vital for large scale sporting events with various sites.[2] however through computer technique of database, personal information can be centralized or managed by accrediting to the sites whose databases keeps up with central database through the website, so as to guarantee the accuracy and conformance of personal information. besides with website information technique schedule management, score management, data statistics and other affairs related to competitive sport can be handled. otherwise the accuracy, immediacy are efficiency are all impossible.

\subsubsection{Enhance the safety of sports competition}

The safety of sports competition as an important goal of large-scale events administration refers to the safety of competition sites and sportsmen's accommodation. for that reason on the 1996 Atlanta Olympic games, the1998 world cup and Sydney Olympic games the electronically identification technology was resorted, concluding digital id and id system. Digital id contains the information of the holder's fingerprint, which can be recognized and checked by entrance Guardia system. in this way not only the competition safety is improved, but the security guard investment is reduced greatly.

\subsubsection{Scientization of sports technique analysis}

In competitive sports lots of skilled movement can't be recognized by eyes, e.g. counting the turns of shoulders and identifying line ball and out of bound in tennis match, while the computer can. nowadays sports technology is analyzed by sensor, building locus model of sportsmen and combining biomechanical principle, based on computer multimedia technology. through sports technology analysis, it is useful to diagnose the defect, make a comparison with excellent sportsman to find the distance and to improve skills under the coach. Giddon Errol, American Israelite physical scientist operates a company of biomechanics computer analysis, which is to analyze sportsman's technology.[3] he found out that ray Wilkins, an American discus thrower, didn't make full use of the function of the braking leg, which caused the strength loss, before he threw out discus. according to the analog computation if this improper action was corrected, Wilkins could improve more than three meters. the result was that he accepted error's advice and broke the world record.

\subsubsection{Scientific stamina monitor}

With the development of modern sports training, the determination of physiological and biochemical indexes of sportsman becomes a compulsory measure, which is also called stamina monitor, concluding the measure of heart rate, electro and lactic acid during sports. the coach can adjust the training from the training load analyzed by computer, so as to achieve scientific training result. sports information technology on one hand can make accurate stamina, on the other hand provide new method for sports training to store lots of historical data, which is significant for the study of sports statistics and analysis.

\subsubsection{Sports information technology promotes the fairness of sports competition}

Hi-teach means can make sports competition more objective and exact by providing solid foundation for sports analysis. in order to preserve the fairness and accuracy, large-scale sports competition prefers digital score system, digital evaluating, digital sense and so on, e.g. installing digital sensor at the end of field race site and pool wall, transmitting the result to information centre as sportsman breasts the tape automatically, installing hawk's eye in tennis competition to record the ball position and speed correctly. the judge of hitch can make out the first and the second only by ting advantage. human wisdom and sports information technology were operated perfectly on Olympic games. the male 100meter champion of Atlanta Olympic games chrysies, was sent off for two fouls, but he didn't agree as the computer demonstrated that his reaction time was 01086 seconds, while less than 0110seconds was stipulate jump the gun, he withdrew from the competition throwing his running shoes unwillingly. therefore we can say that sports information technology is the base of competition fairness and justice and prevent various conflicts.[4]

\subsubsection{To promote sports training effect}

Speediness and high efficiency as two characteristics of computer can improve sports training effect. the function of information storage can record, do some research and make comparison with the data of various training and function index. therefore based on the index, it is useful for coaches to judge the training effect of a period and make training 
schedule of the next period. what's more according to the data of opponents' skills, strategies and pertinent trainings stored in computer, coaches are able to improve sports result. here is a good example, the comparison of Chinese swimmers jingly le, linmin liu and chao na and the foreign swimmers of the same class, showed us that the former dropped behind in skills at the first ten meters. knowing that the swimming coaches improved swimmers' starting skills and the result of the there swimmers mentioned above increased by 015seconds, 0132seconds and 0145seconds, with made certain contribution to Olympic games. Information technology improves sports training effect tremendously, so in the future sports training sports information technology will be one indispensable toll for scientific training.

\section{CONCLUSIONS AND SUGGESTIONS}

\subsection{Conclusions}

It is safe to conclude that sports information technology as new age technology, plays an important role in competitive sports by information zing sports information management, enhancing athletic competition safety, promoting athletic competition fairness and scientific stamina monitor and improving training effect. it is sports information technology that promotes athletic competition, reflects the Olympic games spirit faster, higher stronger sufficiently. At the same time sports information technology is emphasized by every sports powers, who combine sports information technology with hi-tech in competition sports to improve competitive level and show the whole strength of the country. so we can say that in the future sports information technology will become a vital element to improve competitive sports level of every country.

\subsection{Suggestions}

Undoubtedly sports information technology is significant for athletic sports, but is research and application in athletic sports still exist some problems, e.g. superficial cognition, deficient resource development, backward standard and limited research methods. Although china did excellent in holding Olympic games, there are still some limitation in the development and utilization of sports information technology and improving athletic sports compared with other countries. for this reason we should increase sports information technology research research institution educate hitech persons and increase abroad communication etc.

\section{REFERENCES}

[1] Qinzhi Li, Fengxiang Liu. The Development Tendency and Strategy Study of Sports Information, Xi An Institution of Physical Education Journal, 2007(24):7-12.

[2] Parkhouse [American] Sports Administration-Foundation and Application. Beijing: Qinghua University Press, 2003:5.

[3] Ruoguang Wang,Qingzhu Sun. Beijing Interaction of Sports Information and Sports Administration Revolution. Journal of Physical Education, 2008, 15(2): 82-85.

[4] Baijie, The Present Situation and Prospect of Sports Information Technology Application. Sports Culture Guide 2006(9) 48-50. 